\title{
Association of calpain 10 gene UCSNP-43 polymorphism (rs3792267) with polycystic ovarian syndrome
}

\author{
Sujatha Thathapudi ${ }^{1 *}$, Jayashankar Erukkambattu², Qurratulain Hasan ${ }^{3}$, \\ Uma Addepally ${ }^{4}$, Vijayalakshmi Kodati ${ }^{1}$
}

\begin{abstract}
${ }^{1}$ Department of Genetics and Molecular Medicine, Vasavi Medical and Research Centre, Khairatabad, Hyderabad, India

${ }^{2}$ Department of Pathology, Kamineni Academy of Medical Sciences and Research Centre, LB nagar, Hyderabad, India ${ }^{3}$ Kamineni Academy of Medical Sciences and Research Centre, \& Vasavi Medical and Research Center, Hyderabad, India

${ }^{4}$ Department of Biotechnology, Jawaharlal Nehru University of technology, Kukatpally, Hyderabad, India
\end{abstract}

Received: 21 June 2015

Accepted: 10 July 2015

\section{*Correspondence:}

Mrs. Sujatha Thathapudi M.Sc, (PhD),

E-mail: sthathapudi@ymail.com

Copyright: (C) the author(s), publisher and licensee Medip Academy. This is an open-access article distributed under the terms of the Creative Commons Attribution Non-Commercial License, which permits unrestricted non-commercial use, distribution, and reproduction in any medium, provided the original work is properly cited.

\begin{abstract}
Background: The principle features of polycystic ovarian syndrome (PCOS) are insulin resistance (IR), hyperandrogenism (HA), obesity $(\mathrm{Ob})$, oligo/anovulation and polycystic ovaries (PCO). PCOS is known to be associated with increased risk of type-2 diabetes mellitus (T2DM) and genes related to T2DM may also play a role in PCOS pathogenesis. Our aim is to study the association of CAPN-10 gene UCSNP-43 (rs3792267) polymorphism with PCOS.

Methods: Case-control study, involved 204 women with PCOS and 204 healthy, sex and age matched controls. Anthropometric and biochemical profile were taken in a well designed proforma. Isolation of deoxyribonucleic acid (DNA), and genotype analysis was done for all the study population using PCR-RFLP.

Results: No significant difference in allele and genotype frequencies of the CAPN-10, UCSNP- 43 (rs3792267) gene polymorphism were seen between the cases and controls. Frequency of A allele was 0.15 in PCOS and 0.19 in controls (OR 0.7207, CI 0.5 to 1.039 and p value 0.0793 ), indicates that the A allele is not associated with PCOS in our population, and show equal distribution of genotypes in PCOS patients and controls. The AA genotype conferred lack of association for developing PCOS (OR 0.4925, CI 0.1215 to 1.9968 and p value 0.3214 ). But the AA genotype showed elevated body mass index, waist to hip ratio, insulin resistance, triglyceride levels and decreased high density lipoprotein levels when compared to AG and GG genotypes of PCOS patients with controls.

Conclusions: In conclusion, there is no disease risk association of CAPN-10 gene UCSNP-43 (rs3792267) polymorphism with PCOS.
\end{abstract}

Keywords: Polycystic ovarian syndrome, Gene polymorphism, Type 2 diabetes mellitus, Calpain-10

\section{INTRODUCTION}

Polycystic ovary syndrome (PCOS) is one of the most common endocrine dysfunction in women of reproductive age with a prevalence of $5-10 \%$ worldwide, ${ }^{1,2}$ characterized by hyperandrogenism, chronic anovulation, polycystic ovaries (PCO). In addition, many women are insulin resistant and at increased risk of type-2 diabetes mellitus (T2DM). ${ }^{3}$ PCOS is a complex disease with both multiple genetic components and environmental factors 
contributing to its etiology. ${ }^{4}$ Previous studies have established that the prevalence of impaired glucose tolerance and T2DM among women with PCOS has been constantly increasing with consistency across populations of varied ethnic and racial background.,5,6 Calpain-10 (CAPN10) is a candidate gene for T2DM, positionally cloned on $2 \mathrm{q}$ chromosome, ${ }^{7}$ and found to be associated with T2DM in several populations., ${ }^{7,8}$ The aim of the present study was to analyse the role of CAPN-10 genetic susceptibility to PCOS.

\section{METHODS}

Subjects: This study was approved by the Institutional ethical committee and informed written consent was obtained from all subjects. In this prospective casecontrol study we included 204 consecutive PCOS patients from different obstetrics and gynecology centers and general population from July, 2011, to January, 2013. Subjects ranged in age from 17 to $35 \mathrm{yrs}$ and were diagnosed using the 2006-Androgen Excess Society (AES) criteria: 1. hyperandrogenism, clinical or biochemical and either; 2. oligo-anovulation or 3 . polycystic ovarian morphology. All subjects underwent a transvaginal ultrasound or transabdominal ultra sound in the follicular phase to evaluate ovarian morphology and any lesions in the pelvic area.

Exclusion criteria: Women excluded from the study were those with inherited disorders like congenital adrenal hyperplasia, androgen secreting neoplasms, androgenic/anabolic drug use or abuse, Cushing's syndrome, syndromes of severe insulin resistance, thyroid dysfunction and hyperprolactinemia. And there were also 204 controls included in this study over the same period. They visited the health-care center in a super speciality hospital as a part of group check up for work or an individual need for annual comprehensive medical checkup with no specific health problems. Subjects ranged from 17-35 yrs and did not show hirsutism, acne or maletype alopecia. All of them had regular menstrual cycles and none of them satisfied any of the 2006 AES criteria. All control subjects also underwent an ultrasonographic examination, and women who had any pathologic findings like polycystic ovaries were excluded from the study.

Sampling: Two milliliters of peripheral blood was collected in EDTA for DNA isolation, and $5 \mathrm{ml}$ of blood in plain vial for serum preparation from all the patients and controls along with clinical data, personal history and family history.

Biochemical and hormonal findings: Serum preparation was done immediately using centrifuge, and stored in $20^{\circ} \mathrm{C}$ until processing of biochemical parameters. Fasting plasma glucose (enzymatic colorimetric method), Insulin (DRG, USA kits) measured by ELISA method in both patients and controls. Laboratory controls were used to check the accuracy and precision of the analyzer, reagents and assay results.
Metabolic syndrome (Mets): Mets is defined by the National Cholesterol Education Program's Adult Treatment Panel III NCEP (ATP III) report, ${ }^{14}$ presence of three or more of the following risk factors; waist circumference $($ WC) $>88 \mathrm{~cm}$, hypertension $(\mathrm{HTN})>130 / 85$ $\mathrm{mmHg}$ fasting plasma glucose $>6.1 \mathrm{mmol} / \mathrm{L}(101 \mathrm{mg} / \mathrm{dl})$, triglycerides $(\mathrm{TG})>1.7 \mathrm{mmol} / \mathrm{L}(>150 \mathrm{mg} / \mathrm{dl})$, high density lipoprotein $(\mathrm{HDL})<1.3 \mathrm{mmol} / \mathrm{L}(<50 \mathrm{mg} / \mathrm{dl})$.

\section{Isolation of DNA and Genotype Analysis: Genomic DNA} was isolated from the peripheral blood of subjects according to the method routinely used in our laboratory. ${ }^{21}$ The DNA was stored at $-20^{\circ} \mathrm{C}$ until processed. Genotyping for the CAPN-10 UCSNP-43polymorphism (rs3792267) was performed by polymerase chain reaction (PCR) with specific published primers, ${ }^{20}$ forward primer: 5'-GCT GGC TGG TGA CAT CAG TGC-3'; reverse primer: 5'ACC AAG TCA AGG CTT AGC CTC ACC TTC ATA3' synthesized from Sigma - Aldrich Chemical Pvt Limited (Bangalore, India), followed by restriction fragment length polymorphism (RFLP) analysis. A threestep PCR was performed using XP thermal cycler as described by us earlier. ${ }^{22}$ Briefly the PCR conditions included an initial denaturation at $94^{\circ} \mathrm{C}$ for 5 minutes, followed by 35 cycles of denaturation at $94^{\circ} \mathrm{C}$ for 30 seconds, annealing at $62^{\circ} \mathrm{C}$ for 30 seconds and extension at $72^{\circ} \mathrm{C}$ for 30 seconds, final extention at $72^{\circ} \mathrm{C}$ for 5 minutes. The $254 \mathrm{bp}$ amplified PCR product was digested with Nde1 (MBI Fermentas, Hannover, MD), in a total volume of $15 \mu$ for 2 hours at $37^{\circ} \mathrm{C}$, and analyzed on $12 \%$ poly accrylamide gel electrophoresis and staining with silver nitrate. Bands of $254 \mathrm{bp}$ were observed in case of GG genotype, $254 \mathrm{bp}$ and $223 \mathrm{bp}$ in AG genotype, and an undigested 223bp band in AA genotype (Figure 1).

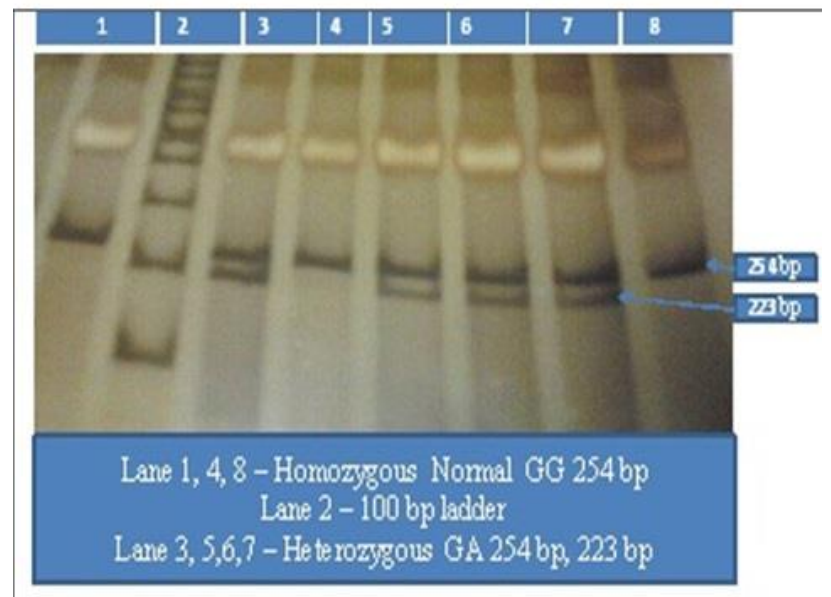

Figure 1: 12\% Polyacrylamide gel electrophoresis of Calpain10 gene polymorphism.

\section{Data and statistics}

Body mass index $=$ weight $/$ height $^{2}\left(\mathrm{~kg} / \mathrm{m}^{2}\right)$ and Insulin resistance (Homeostatic Model Assessment score) was calculated by using the formula: fasting serum insulin $(\mathrm{uU} / \mathrm{ml}) \times$ fasting plasma glucose $(\mathrm{mg} / \mathrm{dl}) / 405 .{ }^{23}$ 
Statistical analysis was performed using "Medcalc" statistical software (MSS), USA. Chi squre test $\left(\mathrm{X}^{2}\right)$, odds ratio (OR), and $95 \%$ confidence interval (CI) were done to assess the association between the groups. One-way ANOVA with post $t$ test was performed using "Graphpad Instat3" software. A p-value of $<0.05$ was considered statistically significant. The Hardy-Weinberg distribution of genotypes in the PCOS and control groups was assessed using a web-tool [ $\mathrm{x}^{2}$ test] Hardy-Weinberg equilibrium calculator, ${ }^{24}$ and were found to be in equilibrium in both patient and control groups.

\section{RESULTS}

Clinical findings: Among 204 patients, the percentages of various clinical hyperandrogenism features like central obesity; 95\%, hirsutism; 92\%, acne; $88 \%$, alopecia; $65 \%$, male pattern of hair loss; $18 \%$, and acanthosis nigricans; $7 \%$ were noted. $70 \%$ of PCOS had shown features of obesity, as per Asia pacific definition of obesity, i.e. body mass index $(\mathrm{BMI}) \geq 25 \mathrm{~kg} / \mathrm{m}^{2}{ }^{25}$

Genetic analysis: A total of 204 PCOS patients and 204 age-matched healthy control women were genotyped for UCSNP-43 polymorphism in the CAPN-10 gene, and genotype and allele frequencies were shown in Table 1. The distribution of $A$ and $G$ allele was equal in both controls and patients. Frequency of A allele was 0.15 in PCOS and 0.19 in controls (OR 0.7207, CI 0.52 to 1.039 and $\mathrm{p}$ value 0.0793 ) indicates that the $\mathrm{A}$ allele is not associated with PCOS in our population, and showed equal distribution of genotypes in PCOS patients and controls. The AA genotype conferred lack of association for developing PCOS (OR 0.4925, CI 0.1215 to 1.9968 and $p$ value 0.3214 ) (Table 2). The genotypes were found to be in Hardy-Weinberg equilibrium in both patient and control groups.

Table 1: Genotypes and Allele frequencies of Calpain 10 Polymorphism identified in the study.

\begin{tabular}{|llllll|}
\hline $\begin{array}{l}\text { Calpain } \\
10\end{array}$ & GG & AG & AA & $\begin{array}{l}\text { A } \\
\text { allele }\end{array}$ & $\begin{array}{l}\text { G } \\
\text { allele }\end{array}$ \\
\hline \multirow{2}{*}{ Patients } & 146 & 55 & 03 & 61 & 347 \\
& $(71.56 \%)$ & $(26.9 \%)$ & $(1.4 \%)$ & $(0.15)$ & $(0.85)$ \\
\hline \multirow{2}{*}{ Controls } & 130 & 68 & 06 & 80 & 328 \\
& $(63.72 \%)$ & $(33.33 \%)$ & $(2.94 \%)$ & $(0.19)$ & $(0.81)$ \\
\hline
\end{tabular}

Allele frequency odds ratio $0.7207 ; 95 \%$ CI 0.5 to 1.039 $\mathrm{P}$ value $=0.0793$

Table 2: Statistical analysis of Genotypes of Calpain 10 polymorphism identified in the study.

\begin{tabular}{|llllll|}
\hline Genotype & PCOS & Controls & $\begin{array}{l}\text { Odds } \\
\text { ratio }\end{array}$ & $95 \%$ CI & $\begin{array}{l}\text { P } \\
\text { value }\end{array}$ \\
\hline $\begin{array}{l}\text { AA vs } \\
\text { AG+GG }\end{array}$ & $03 / 201$ & $06 / 198$ & 0.4925 & $\begin{array}{l}0.1215- \\
1.9968\end{array}$ & 0.3214 \\
\hline $\begin{array}{l}\text { AG vs } \\
\text { AA+GG }\end{array}$ & $55 / 149$ & $68 / 136$ & 0.7383 & $\begin{array}{l}0.4828- \\
1.289\end{array}$ & 0.1614 \\
\hline $\begin{array}{l}\text { GG vs } \\
\text { AA+AG }\end{array}$ & \multirow{2}{*}{$146 / 58$} & $130 / 74$ & 1.4329 & $\begin{array}{l}0.9442- \\
2.174\end{array}$ & 0.0910 \\
\hline
\end{tabular}

vs - versus, PCOS - Polycystic Ovarian Syndrome, OR - Odds Ratio, CI - Confidence Interval, p - significance

Biochemical findings: Significant increase in fasting insulin, HOMA score, Triglyceride levels and decreased levels with high density lipoprotein levels were observed in PCOS patients when compared with controls (Table 3). $10.78 \%$ and $9.8 \%$ of our PCOS cases showed T2DM and hypertension (HTN). In the family history we have noticed $70 \%$ of T2DM, $51 \%$ of HTN.

Table 3: Distribution of Calpain 10 genotypes, anthropometric and biochemical parameters in patients and controls and their comparison with mean and standard deviation.

\begin{tabular}{|llllllll|}
\hline \multirow{2}{*}{ Parameters } & A/A genotype & \multicolumn{3}{c}{ A/G genotype } & \multicolumn{2}{l|}{ G/G genotype } \\
& PCOS & Controls & PCOS & Controls & PCOS & Controls & P value \\
\hline Age in yrs & $30+2.4$ & $25.5+5.8$ & $29.05+4.08$ & $26+9.4$ & $27.9+3.4$ & $27.89+5.17$ & $0.0415^{*}$ \\
\hline BMI $\left(\mathrm{kg} / \mathrm{m}^{2}\right)$ & $27.33+0.57$ & $22.33+2.06$ & $27.13+5.2$ & $23.5+2.7$ & $27.11+4.8$ & $23.3+3.02$ & $0.0001^{*}$ \\
\hline W/H & $0.95+0.040$ & $0.79+0.06$ & $0.94+0.05$ & $0.79+0.05$ & $0.93+0.06$ & $0.79+0.05$ & $<0.0001^{*}$ \\
\hline F gl $(\mathrm{gm} / \mathrm{dl})$ & $88+9.5$ & $90+7.8$ & $88.77+10.15$ & $88.69+8.18$ & $88.16+11.8$ & $88.8+13.1$ & 0.9962 \\
\hline F ins uIU/ml & $12.3+3.05$ & $7.8+3.5$ & $12.14+7.8$ & $6.6+3.4$ & $12.6+8.7$ & $6.75+3.24$ & $<0.0001^{*}$ \\
\hline HOMA score & $5.1+2.36$ & $1.5+0.7$ & $2.8+2.1$ & $1.45+0.9$ & $3.16+2.7$ & $1.4+0.7$ & $<0.0001^{*}$ \\
\hline Chol gm/dl & $140+20$ & $145.3+17$ & $157.8+30$ & $166.5+34.2$ & $163.17+30$ & $160+32.4$ & 0.2878 \\
\hline HDL gm/dl & $35.3+7.5$ & $44.16+5.7$ & $36.6+5.3$ & $44.6+10.8$ & $40.8+9.4$ & $45.18+9.99$ & $<0.0001^{*}$ \\
\hline TGL gm/dl & $154.6+34$ & $70.5+21.9$ & $132.01+48.2$ & $103.6+32.8$ & $123.89+44$ & $94.5+29$ & $<0.0001^{*}$ \\
\hline LDL gm/dl & $72.3+21.5$ & $82+21$ & $95.5+31$ & $100+52$ & $98.14+28.5$ & $97.1+37.6$ & 0.6932 \\
\hline VLDL gm/dl & $30.6+6.5$ & $14.16+4.4$ & $26.6+9.5$ & $20.4+4.0$ & $24.4+8.3$ & $20.10+7.6$ & $<0.0001^{*}$ \\
\hline
\end{tabular}

Data are shown as mean \pm SD

$P$ values were evaluated by one-way analysis of variance (ANOVA) with post-test

*Significant values ( $\mathrm{p}$ is $<0.05$ )

Abbreviations: Ht, height; Wt, weight; BMI, body mass index; W/H, waist to hip ratio; F glu, fasting glucose; F ins, fating insulin; HOMA, homeostatic model assessment score; Chol-Cholesterol; HDL, High density lipoprotein; TGL, Tryglycerides; LDL, Low density lipoprotein; VLDL, Very low density lipoprotein. 
Metabolic Syndrome: In the present study $25 \%$ of PCOS and $4 \%$ of controls showed features of metabolic syndrome as per the definition of NCEP ATP III criteria. ${ }^{14}$

\section{DISCUSSION}

PCOS, as per Androgen excess society-2006 criteria, 1,2 is mainly characterized by hyperandrogenemia, anovulatory infertility and polycystic ovaries. In addition to these, many PCOS women are insulin resistant and are at high risk to develop type 2 diabetes mellitus (T2DM). ${ }^{3}$ PCOS is a complex disease with both multiple genetic components and environmental factors contributing to its etiology. ${ }^{4}$ The CAPN10 gene, encoding a ubiquitous member of calpain-like cysteine protease family, was positionally cloned on $2 \mathrm{q}$ chromosome within NIIDM1 region, ${ }^{7}$ and found to be associated with T2DM in several populations. ${ }^{7,8}$ Most of the subsequent studies found association of CAPN-10 gene with PCOS phenotypes as well. ${ }^{9-12}$ CAPN-10 is essential for calcium-regulated intracellular signaling, and plays a crucial role in proinsulin processing, insulin secretion, action, and sensitivity. ${ }^{28}$ The presence of Calpain-10 mRNA in pancreatic islets, muscle, and liver, the three important organs which are concerned with blood glucose regulation, suggests that Calpain-10 may regulate pathways that affect insulin action, hepatic glucogenesis, each of which is altered in patients with T2DM. ${ }^{28}$ UCSNP-43 has been strongly associated with T2DM and insulin resistance, and both UCSNP-43 and 44 have been implicated in the transcriptional regulation of the CAPN10 gene. ${ }^{7}$ The first evidence of Calpain-10 role in PCOS was given by Gonzalez et al, ${ }^{29}$ in which they showed that CAPN10 UCSNP-44 allele was significantly associated with PCOS in Spanish population. Haddad et al did not find any disease risk association of CAPN10 gene variants with PCOS. ${ }^{13}$

Metabolic syndrome (MS) is characterized by abdominal obesity, atherogenic dyslipidemia, raised blood pressure, insulin resistance, and proinflammatory state. ${ }^{14}$ Currently insulin resistance is considered the underlying mechanism for these metabolic alterations. ${ }^{15,16}$ The CAPN-10 gene has been associated with several components of MS such as hypertension in Chinese $^{17}$ and African-American, ${ }^{18}$ elevated body mass index in Japanese, ${ }^{19}$ hyper-triglyceridemia in obese Swedish individuals. ${ }^{20}$ In the present study, we identified $25 \%$ PCOS and $4 \%$ control population qualifying for metabolic syndrome (Mets) as per definition of Mets in National Cholesterol Education Programme, Adult Treatment Panel III (NCEP ATP III), ${ }^{14}$ though we had noticed $60 \%$ of insulin resistance and $10.78 \%$ of T2DM in our PCOS. Obesity, especially central adiposity manifests as the main clinical feature in PCOS. It has been reported that approximately $50 \%$ of PCOS women are overweight or obese, and most of them have central obesity. ${ }^{31}$ Based on Asia-Pacific definition of obesity, ${ }^{25}$ in our study, we noticed $70 \%$ of PCOS patients were obese. This high prevalence can be attributed to food habits and lifestyles of Indian women. We have noticed elevated BMI with AA genotype similar to Japanese study, ${ }^{19}$ and elevated triglyceride levels with AA genotype similar to Swedish population. ${ }^{20}$

The significance of the association between SNPs/haplotypes with PCOS is underlined by the positive correlation between two adjacent SNPs -UCSNP-43, UCSNP-44, specifically with hyperandrogenemia features that are central to PCOS. ${ }^{12,28}$ Dasgupta et al, ${ }^{30}$ explored the possible association of CAPN10 gene variants with risk for PCOS, in a large cohort of South Indian women, and found that UCSNP-44 was significantly associated with PCOS, other variants like UCSNP-43, 56, 19, and 63 did not show any association. In the present study we did not find any variation in allele or genotype frequencies of PCOS and controls (Table 1) and there is no disease risk association of CAPN10 UCSNP-43 polymorphism with PCOS (Table 2), similar to Dasgupta et al, Haddad et al. ${ }^{30,13}$

Wiltgen et $\mathrm{al}^{26}$ did not find a direct association between UCSNP43, UCSNP19 and UCSNP63 and susceptibility of PCOS in Brazilian patients, similar to our study and Haddad et al, Dasgupta et al., but they found an association between higher prevalence of the UCSNP43 polymorphic allele of the CAPN10 gene and metabolic syndrome in PCOS women. In the present study, the AA genotype showed elevated values in body mass index (BMI), waist to hip ratio (WHR), homeostatic model assessment model score (HOMA), triglyceride levels and very low density lipoproteins levels, and decreased levels of high density lipoprotein levels, compared to AG and GG genotypes of PCOS and controls. Contrary to our study Marquez et $\mathrm{al}^{27}$ suggested that the presence of uncommon (A) allele for UCSNP43 was significantly associated to PCOS.

In the present study we were able to see the significant variation in anthropometric and metabolic parameters in the genotypes, but unable to find the disease risk association of UCSNP-43 to PCOS, due to less number of study population. Study in a larger cohorts of ethnically diverse populations of India is required to better understanding of CAPN10 polymorphism in PCOS.

\section{CONCLUSION}

There is no disease risk association of CAPN-10 gene UCSNP-43 (rs3792267) polymorphism with PCOS. But significant difference in the mean values of body mass index, insulin resistance and dyslipidemia were observed with variant genotype (AA) of UCSNP-43 CAPN10 gene polymorphism in our PCOS population compared to controls. 


\section{ACKNOWLEDGEMENTS}

1. We thank Department of Science and Technology, (New Delhi, India) for granting fund. Grant Number: (SR/LS- 91/2011/WOS-A),

2. We thank all the participants of the study,

3. We thank management of Vasavi Medical and Research Center, Kamineni Academy of Medical Sciences and Research Centre, and Anu's fertility center, Hyderbad for their valuable support.

Funding: (SR/LS-91/2011/WOS-A), Department of Science and Technology, Women Scientist-A, New Delhi, India.

Conflict of interest: Nil

Ethical approval: Hospital ethical committee approved

\section{REFERENCES}

1. Azziz R, Carmina E, Dewailly D, DiamantiKandarakis E, Escobar-Morreale HF, Futterweit W, et al. Position statement: Criteria for Defining PCOS as a Predominantly Hyperandrogenic Syndrome: An Androgen Excess Society Guideline. J Clin Endocrinol Metab 2006;91:4237-45.

2. Azziz R, Carmina E, Dewailly D, DiamantiKandarakis E, Escobar-Morreale HF, Futterweit W, et al. The Androgen Excess and PCOS Society criteria for the Polycystic ovarian syndrome: the complete task force report. Fertil and Steril 2009;91(2):456-88.

3. Ehrmann DA, Barnes RB, Rosenfield RL, Cavaghan MK, Imperial J. Prevalence of impaired glucose tolerance and diabetes in women with polycystic ovary syndrome. Diabetes Care 1999; 22: 141-46.

4. Carmina E. Genetic and Environmental aspect of polycystic ovary syndrome. J Clin Endocrinol Invest 2003;26:1151-9.

5. Legro RS, Kunselman AR, Dodson WC, Dunaif A. Prevalence and predictors of risk for type 2 diabetes mellitus and impaired glucose tolerance in polycystic ovary syndrome: a prospective, controlled study in 254 affected women. J Clin Endocrinol Metab 1999; 84 :165-69.

6. Ehrmann DA. Glucose Intolerance in Polycystic Ovary Syndrome: Role of Beta cell In: Chang RJ, Heindel JJ, Dunaif A, eds. Polycystic Ovary Syndrome. New York: Marcel Dekker Inc. 2002: 89103.

7. Horikawa Y, Oda N, Cox NJ, Li X, Orho-Melander M, Hara $M$, et al. Genetic variation in the gene encoding calpain-10 is associated with type 2 diabetes mellitus. Nat Genet 2000;26:163-75.

8. Evans JC, Frayling TM, Cassell PG, Saker PJ, Hitman GA, Walker M, et al. Studies of association between the gene for Calpain-10 and type 2 diabetes mellitus in the United Kingdom. Am J Hum Genet 2001;69:544-52.

9. Ehrmann DA, Schwarz PE, Hara M, Tang X, Horikawa Y, Imperial $J$, et al. Relationship of
Calpain-10 genotype to phenotypic features of polycystic ovary syndrome. J Clin Endocrinol Metab 2002; 87:1669-73.

10. Gonzalez A, Abrill E, Roca A, Aragon MJ, Figueroa MJ, Velarde P, et al. Comment: Calpain10 alleles are associated with polycystic ovary syndrome. J Clin Endocrinol Metab 2002; 87:3971-76.

11. Vollmert C, Hahn S, Lamina C, Huth C, Kolz M, Schopfer-Wendels A, et al. Calpain-10 variants and haplotypes are associated with polycystic ovary syndrome in Caucasians. Am J Physiol Endocrinol Metab 2007; 292: E836-44.

12. Escobar-Morereale HF, Peral B, Villuendas G, Calvo RM, Sancho J, San Millan JL. Common single nucleotide polymorphisms in intron 3 of the calpain10 gene influence hirsutism. Fertil Steril 2002; 77: 581-87.

13. Haddad L, Evans JC, Gharani N, Robertson C, Rush $\mathrm{K}$, Wiltshire $\mathrm{S}$, et al. Variation within the type 2 diabetes susceptibility gene calpain-10 and polycystic ovary syndrome. J Clin Endocrinol Metab 2002; 87:2606-10

14. Third report of the National Cholesterol Education Program (NCEP) Expert Panel on Detecion, Evaluation, and Treatment of High Blood Cholesterol in Adults (Adult Treatment Panel III) final report. Circulation 2002; 106:3413-21.

15. Ferrannini E, Haffner SM, Mitchell BD, Stern MP. Hyperinsulinemia: the key feature of a cardiovascular and metabolic syndrome. Diabetologia 1991; 34: 416-22.

16. Reaven GM. Banting lecture. Role of insulin resistance in human disease. Diabetes 1998; 37:1595-07.

17. Chen SF, Lu XF, Yan WL, Huang JF, Gu DF. Variations in the Calpain 10 gene are associated with the risk of type 2 diabetes and hypertension in northern Han Chinese population. Chin Med J (Engl) 2007; 120: 2218-23.

18. Garant MJ, Kao WH, Brancati F, Coresh J, Rami TM, Hanish CL, et al. SNP 43 of CAPN10 and the risk of type 2 Diabetes in African-Americans: the Atherosclerosis Risk in Communities Study. Diabetes 2002;51:231-37.

19. Shima Y, Nakanishi K, Odawara M, Kobayashi T, Ohta H. Association of SNP-19 genotype 22 in the Calpain-10 gene with elevated body mass index and hemoglobian A1c levels in Japanese. Clin Chim Acta 2003;336:89-96.

20. Carlsson E, Fredriksson J, Groop L, Ridderstale M. Variation in the Calpain-10 gene is associated with elevated triglycerides levels and reduced adipose tissue messenger ribonucleic acid expression in Swedish subjects. J Clin Endocrinol Metab 2004; 89:3601-05.

21. Govindan S, Ahamad SN, Vedicherla B, Kodati V, Rao KP, Ahuja YR, Hasan Q. Association of Progesterone receptor gene polymorphism (PROGINS) with endometriosis, uterine fibroids and breast cancer. Cancer Biomark 2007;3:73-8. 
22. Kodati VL, Shetty P, Vattam K, Govindan S, Shaik NA and Hasan Q. Tumor necrosis factor alphaC850T polymorphism is significantly associated with endometriosis in Asian Indian women. Fertil and Steril 2010;94(2):453-56.

23. Liang SJ, Hsu CS, Tzeng CR, Chen $\mathrm{CH}$, and $\mathrm{Hsu}$ MI. Clinical and Biochemical parameters of Polycystic Ovary Syndrome between the age of 20 and 40. Hum reprod 2011;12:3443-49.

24. Rodriguez S, Gaunt TR, Day IN. Hardy-Weinberg Equilibrium Testing of Biological Ascertainment for Mendelian Randomization studies. Am J Epidemiol 2009; 169:505-14.

25. Chen X, Ni R, Mo Y, Li L, Yang D. Appropriate BMI levels for PCOS patients in Southern China. Hum Reprod 2010;25:1295-02.

26. Wiltgen D, Furtado L, Kohek MB, Spritzer PM. CAPN10 UCSNP-43, UCSNP-19 and UCSNP-63 polymorphisms and metabolic syndrome in polycystic ovary syndrome. Gynecol Endocrinol 2007;23(3):173-78.

27. Marquez JL, Pacheco A, Valdes P, Salazar LA. Association between CAPN10 UCSNP-43 gene polymorphism and polycystic ovary syndrome in Chilean women. Clin Chim Acta 2008;398(12):5-9.
28. Sreenan SK, Zhou YP, Otani K, Hansen PA, Currie $\mathrm{KP}$, Pan CY, et al. Calpains play a role in insulin secretion and action. Diabetes 2001;50:2013-20.

29. Gonzalez A, Abril E, Roca A, Aragon MJ, Figueroa MJ, Velarde P, et al. Specific CAPN10 gene haplotypes influence the clinical profile of polycystic ovary patients. J Clin Endocrinol Metab 2003;88:5529-36.

30. Dasgupta S, Sirisha PVS, Neelaveni K, Anuradha K, Reddy BM. Association of CAPN10 SNPs and Haplotypes with Polycystic Ovary Syndrome among South Indian Women. PLoS ONE 2012;7(2):e32192.

31. Gambineri A, Pelusi C, Vicennati V, Pagotto U, Pasquali R. Obesity and the polycystic ovarian syndrome. Int $\mathbf{J}$ Obes Relat Metab Disord 2002;26:883-96.

Cite this article as: Thathapudi S, Erukkambattu J, Hasan Q, Addepally U, Kodat V. Association of Calpain 10 Gene UCSNP-43 Polymorphism (rs3792267) with Polycystic Ovarian Syndrome. Int J Reprod Contracept Obstet Gynecol 2015;4:1185-90. 